
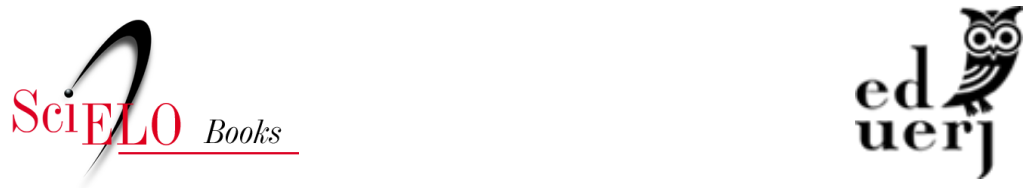

\title{
Capítulo 3. As contribuições da autoscopia na formação de professores sobre o uso do Currículo Funcional Natural destinado aos alunos com Transtorno do Espectro Autista
}

\author{
Cláudia Miharu Togashi \\ Cátia Crivelenti de Figueiredo Walter
}

\section{SciELO Books / SciELO Livros / SciELO Libros}

TOGASHI, C. M., and WALTER, C. C. F. As contribuições da autoscopia na formação de professores sobre o uso do Currículo Funcional Natural destinado aos alunos com Transtorno do Espectro Autista. In: NUNES, L. R. D. P., ed. Autoscopia: uma ação reflexiva sobre a prática docente [online]. Rio de Janeiro: EDUERJ, 2020, pp. 89-111. ISBN: 978-65-8794910-9. https://doi.org/10.7476/9786587949109.0005.

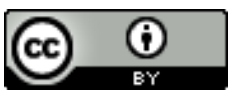

All the contents of this work, except where otherwise noted, is licensed under a Creative Commons Attribution 4.0 International license.

Todo o conteúdo deste trabalho, exceto quando houver ressalva, é publicado sob a licença Creative Commons Atribição 4.0.

Todo el contenido de esta obra, excepto donde se indique lo contrario, está bajo licencia de la licencia Creative Commons Reconocimento 4.0. 


\title{
Capítulo 3
}

\section{As contribuiçóes da autoscopia na formação de professores sobre o uso do Currículo Funcional Natural destinado aos alunos com Transtorno do Espectro Autista}

\author{
Cláudia Miharu Togashi \\ Cátia Crivelenti de Figueiredo Walter
}

\section{Introduçáo}

As dificuldades no processo de incluir alunos com Transtorno do Espectro Autista (TEA) no sistema regular de ensino, infelizmente, ainda se fazem presentes. Nesse sentido, um dos fatores que corrobora a existência dessas lacunas no processo educacional é a falta de conhecimentos específicos dos professores para lidar com o público-alvo em questão. Muitos profissionais ainda se sentem despreparados para assumir uma turma que tenha alunos incluídos, e, no caso de crianças com TEA, a preocupação aumenta de proporção. $\mathrm{O}$ fato de o transtorno ocasionar dificuldades na comunicação oral e não verbal, na interação social, fazendo com que pessoas nessa condição apresentem comportamentos peculiares e repertório de interesses restritos, em diferentes graus e possibilidades, acaba gerando muita angústia e insegurança nos professores (Camargo e Bosa, 2009; Schmitd et al., 2016). 
Por esses e outros motivos, a formação continuada é fundamental para o desenvolvimento profissional do professor, no sentido de proporcionar novos conhecimentos, favorecendo a prática pedagógica e diminuindo o sentimento de despreparo e de medo, de modo a garantir mais segurança na atuação junto ao aluno incluído. Além disso, Silva et al. (2016, p. 6) destacam que a formação de professores é "uma ação decisiva para a efetivação das políticas de inclusão educacional e para o processo educacional pleno da pessoa com deficiência".

Considerando que as dificuldades da inclusão escolar não se devem exclusivamente às questóes da formaçáo continuada dos profissionais da Educação, mas também a outros inúmeros fatores, ainda assim, é necessário discutir a qualidade da aprendizagem dos alunos público-alvo da Educaçáo Especial. Diferentemente do que era dito - que a inclusão deveria acontecer para socializar a criança com deficiência com seus pares -, o que se discute atualmente diz respeito aos processos educacionais inclusivos que devem buscar práticas eficazes a fim de atender às demandas específicas do público-alvo da Educaçáo Especial.

As dificuldades de comunicação, como a fala funcional ou até mesmo o uso de gestos e da comunicação não verbal, estão muito presentes nos alunos com TEA. Tais dificuldades são muito citadas pelos professores como um dos fatores que mais interfere no processo de ensino e aprendizagem desses alunos (Walter e Nunes, 2013).

Tendo em vista que crianças com TEA têm dificuldades de comunicação oral, pode-se pensar em estratégias de intervenção para que elas consigam ser compreendidas e possam se expressar a partir do uso da Comunicação Alternativa e Ampliada (CAA). A CAA pode ser considerada como um eficaz auxílio em práticas inclusivistas no que se refere a dar voz aos alunos sem fala funcional. Essa estratégia implica o uso de sistemas e recursos alternativos à comunicação oral que oferecem aos indivíduos desprovidos dessa 
função (ou com limitaçôes) possibilidades para se comunicar. Tais mecanismos são elaborados por meio de sistemas manuais como alguns sinais e por sistemas gráficos que são os símbolos pictográficos, ideográficos e arbitrários, a fim de substituir ou suplementar a fala humana, com outras formas de comunicação (Nunes, 2003).

Outra proposta de intervenção educacional pensada para alunos com deficiência, como Deficiência Intelectual e TEA, denominada Currículo Funcional Natural (CFN), tem sido considerada por alguns pesquisadores uma estratégia positiva no processo de aprendizagem e no auxílio do desenvolvimento do aluno (Giardinetto, 2005; Cuccovia, 2003). A esse respeito, Mayo et al. (2008) definem como objetivo geral do CFN ensinar conhecimentos e habilidades que possam ser usados e úteis para o aluno durante seu tempo de vida. Visa também a tornar o aluno mais independente e produtivo, além de mais aceito socialmente (Leblanc, 1982). Tendo o CFN como uma estratégia que valoriza as potencialidades e busca o desenvolvimento e a independência dos alunos, o presente trabalho buscou unir algumas das propostas de atuação baseadas na referida metodologia, por meio de práticas pedagógicas mais funcionais, pensadas para favorecer o aluno com TEA que esteja em processo de inclusão escolar a partir da formação continuada de professoras que atuam diretamente com esses alunos - público-alvo da Educação Especial.

A literatura aponta para diferentes propostas e modelos de formações continuadas oferecidos aos profissionais da área da Educação. Um procedimento que vem demonstrando sucesso é a autoscopia, que também tem sido utilizada para a reflexão das práticas pedagógicas. Nessa perspectiva, Sadalla e Larocca (2004, p. 419) descrevem a autoscopia como "um recurso de videogravação de uma prática, visando a análise e autoavaliação por um ou mais protagonistas desta prática".

Segundo Silva e Nunes (2017), essa proposta tem o intuito de proporcionar aos professores a atividade de filmar suas aulas 
em registros de vídeo. Posteriormente ao registro, é realizada uma análise do desempenho dos professores, onde são recortados trechos dos vídeos e discutidos entre o grupo de formação. Conforme Leite (2012), a Autoscopia é um procedimento de confrontação dos professores pelo intermédio do material coletado e editado mediante a situação que se deseja ser refletida e avaliada sob a nova ótica de promover atividades e procedimentos mais eficazes ao lidar com as dificuldades apresentadas em sala de aula.

\section{Objetivo}

O presente trabalho é um recorte de uma tese de doutorado e objetiva descrever os efeitos da oferta de um curso de formação continuada pela pesquisadora às professoras do Atendimento Educacional Especializado (AEE) com estratégias da autoscopia, tendo como embasamento os pressupostos metodológicos e práticos do Currículo Funcional Natural (CFN).

\section{Método}

A metodologia adotada tem como base os participantes, os locais, os materiais utilizados, bem como os procedimentos gerais e específicos, sendo detalhada a seguir.

\section{Participantes}

Participaram deste estudo três professoras do Atendimento Educacional Especializado que atuavam em Sala de Recursos Multifuncional (SRM) de uma rede municipal de ensino do Rio de Janeiro, atendendo, cada uma, um aluno com diagnóstico de Trans- 
torno do Espectro do Autismo (TEA) sem comunicação oral. As principais descriçôes das professoras serão apresentadas a seguir. ${ }^{10}$

a. Maria, 59 anos de idade, atendia em uma Sala de Recursos em uma escola localizada na Zona Norte do Rio de Janeiro. Atua há 40 anos no magistério, fez a formação inicial no antigo Curso Normal e, posteriormente, cursou Letras. Com experiência de 27 anos na Educação Especial, começou como professora de Classes Especiais com turma de Deficiência Visual e atualmente trabalha na Sala de Recursos Multifuncional.

b. Gabriela, 49 anos de idade, atendia em uma Sala de Recursos Multifuncional em uma escola localizada na Zona Sul do Rio de Janeiro. É formada há 15 anos em Letras, não possui qualquer formação em Educação Especial. Atua há 2 anos na Sala de Recursos Multifuncional. Disse, na entrevista com a pesquisadora, que não se considerava uma profissional capacitada a trabalhar com o público-alvo da Educação Especial, pelo que entende do que seja atender de forma adequada esses alunos especificamente.

c. Sandra, 52 anos de idade, atuava em uma Sala de Recursos Multifuncional em uma escola localizada na Zona Sul. Possui 25 anos de magistério, dos quais 18 foram atuando na Educação Especial (na sala de recursos e como parte de uma Equipe de Acompanhamento da Educação Especial). É formada em Fonoaudiologia e licenciada em Ciências e Biologia e fez pós-graduação em Atendimento Educacional Especializado online pelo Ministério da Educação (MEC).

${ }^{10}$ Os nomes das participantes professoras foram alterados para manter o sigilo das suas verdadeiras identidades. 
Os participantes alunos também terão suas características descritas a seguir. ${ }^{11}$ Ressalta-se que as informaçôes foram obtidas a partir de entrevistas realizadas com as responsáveis legais dos alunos, após a assinatura do Termo de Consentimento Livre e Esclarecido (TCLE).

a. Victor, quatro anos de idade, matriculado na Educação Infantil, possui diagnóstico de TEA desde os três anos. As principais queixas da família foram em relação à ausência da fala na criança, à interação social diferente e ao comportamento muito agitado.

b. Paulo, dez anos de idade, matriculado no 3..$^{\circ}$ ano do Ensino Fundamental, ainda não possui laudo de TEA. A mãe sinalizou que ele se comunica por meio de gestos (aponta para os itens desejados) e possui muitos comportamentos inadequados (na rua, ele se joga no chão; bate e puxa o cabelo de outras pessoas).

c. Marcos, oito anos de idade, está matriculado no 2. ${ }^{\circ}$ ano do Ensino Fundamental. A mãe contou que a primeira característica percebida foi a ausência na comunicação oral e de interação social com as outras crianças na creche que ele frequentava. Ela contou que não costuma levá-lo em mercados, tampouco se sente confortável em sair com a criança em outros ambientes, pois há muitos comportamentos inadequados como gritos ou choros.

2. Locais

O curso de formação continuada ocorreu em uma Sala de Recursos Multifuncional de um município do Rio de Janeiro.

${ }^{11}$ Os nomes dos participantes alunos também foram alterados para preservar suas identidades. 
Como atividade prévia, cada professora realizou a filmagem da sua atuação com os respectivos alunos nas próprias salas de recursos, cujas localizaçóes já foram citadas no item anterior.

\section{Materiais utilizados}

Os recursos utilizados ao longo da investigação foram: material teórico para fomentar a discussão ao longo do curso, projetor multimídia, notebook, filmadora, Relatório de Observação para o registro da sessão, papéis, plastificadoras, impressora, velcros com adesivos, imagens do site ARASAAC, materiais escolares e aparelhos celulares próprios das professoras para realizar as filmagens.

\section{Procedimentos gerais}

Primeiramente, a pesquisa foi enviada à Plataforma Brasil; em seguida, encaminhada para apreciação do Comitê de Ética em pesquisa da Universidade do Estado do Rio de Janeiro (UERJ), sendo aprovada sob o Parecer N. ${ }^{\circ}$ 1.979.561. Concomitantemente ao primeiro procedimento supracitado, a pesquisa foi apresentada à Secretaria de Educaçáo do Município do Rio de Janeiro, tendo sido autorizada para realização, de acordo com o Processo N.o 07/008.439/2016.

Posteriormente, a pesquisadora se apresentou para todas as Direçóes Escolares a fim de entrar em contato com possíveis professoras do AEE que estariam dispostas e interessadas em participar da pesquisa. Selecionadas as participantes professoras, as famílias dos alunos com TEA foram contatadas para verificar o interesse na participação da criança na pesquisa. Após a assinatura do Termo de Consentimento Livre e Esclarecido autorizando a participação na pesquisa de todos os participantes, deu-se início aos procedimentos específicos da investigação. 
96 Autoscopia: uma ação reflexiva sobre a prática docente

\section{Procedimentos específicos}

Os procedimentos específicos foram realizados em quatro etapas, que serão descritas a seguir.

\section{a. Filmagem inicial}

A pesquisadora orientou as três professoras de AEE a realizarem cinco filmagens em dias diferentes, sem interrupçóes, com aproximadamente dez minutos cada uma, em situaçóes de interação com seus respectivos alunos, no momento de atendimento na sala de recursos. É válido ressaltar que, nessa fase, as orientaçóes dadas às participantes professoras foram apenas a respeito da filmagem, ou seja, não foi dada qualquer dica sobre a atuação nas práticas pedagógicas. As principais observaçóes realizadas com base nas filmagens iniciais que mostraram a atuação das professoras de AEE junto aos seus alunos serão descritas em seguida:

- Professora Maria e aluno Victor: a professora Maria buscava desenvolver atividades voltadas para o esquema corporal, pois foi a proposta do planejamento que desenvolveu em conjunto com a professora de turma do aluno. Buscava interagir sempre com Victor, incentivando-o nas propostas de atividades pedagógicas. Victor não apresentava fala articulada e foi percebida pouca intensidade de interaçấo com a professora, pouca troca de olhares e pouca solicitação da professora nas tarefas propostas. Náo foi observado o uso da CAA nas atividades com o aluno.

- Professora Gabriela e aluno Paulo: a professora trabalhava com músicas com o aluno Paulo. Geralmente, as músicas eram bem infantilizadas para a idade dele. A professora sinalizou dificuldades em relação aos comportamentos inadequados de Paulo, bem como na apresentação da proposta e na realização de atividades dirigidas. Usou como estratégia de intervenção com o aluno o trabalho com 
o esquema corporal e a musicalização. Ao longo das sessóes iniciais, ele apresentava muitos comportamentos inadequados como se jogar ao cháo, puxar o cabelo da professora, bater e arremessar objetos na sala. Comunicava-se por meio do gesto (apontando os itens desejados). Não foi observado o uso da CAA nas atividades com Paulo.

- Professora Sandra e aluno Marcos: a professora desenvolvia atividades com diferentes propostas e com muitos materiais pedagógicos diferenciados, muitas vezes produzidos por ela, para tentar descobrir gostos e interesses do aluno. Trabalhou com brinquedos, jogos, músicas, notebook, a fim de incentivar o interesse dele nas atividades. Marcos não apresentava fala funcional, mas gritava muito para sinalizar quando algo não o agradava. Não foi observado o uso da CAA nas atividades com o aluno.

\section{b. Curso de Capacitação}

Após receber as cinco filmagens iniciais das professoras do AEE, a pesquisadora organizou o curso de formaçấo continuada. Nesse processo, foram realizados seis encontros ao longo de cinco meses, com duração média de quatro horas diárias. Os encontros eram divididos em dois momentos: o primeiro consistia no procedimento de autoscopia, para que as professoras do AEE pudessem refletir sobre sua prática; e, no segundo momento, eram discutidas as questôes teóricas sobre alguns temas pertinentes para orientar a prática pedagógica das professoras.

Para a realização da autoscopia, foi usada uma sessão da filmagem inicial de cada professora, e trechos previamente selecionados eram apresentados às professoras para confrontar suas atitudes e seus comportamentos, questionando sobre aquele dado momento da filmagem. Após as falas e impressóes da professora, eram feitas algumas orientaçóes, e, posteriormente, a fala era aberta para as 
demais professoras participantes, gerando uma discussão coletiva durante a formação.

O segundo momento de discussão teórica foi realizado com a leitura de textos sobre TEA, Comunicaçáo Alternativa e Ampliada e Currículo Funcional Natural, além de a pesquisadora ensinar as professoras do AEE a elaborar cartôes de CAA, a confeccionar os materiais e a utilizar com os alunos ao longo dos atendimentos. Os encontros do curso de capacitaçáo serão descritos a seguir:

\section{Encontro 1}

No primeiro momento do encontro 1, foram apresentados às professoras alguns trechos previamente selecionados pela pesquisadora a respeito das primeiras sessóes filmadas por elas próprias, registrando o momento do trabalho pedagógico realizado com seus respectivos alunos, a fim de dar início ao trabalho de autoscopia. Para ilustrar tal momento, será apresentado um trecho desse primeiro encontro de formação continuada, no qual a pesquisadora apresentou trechos da filmagem com a atuação da professora Gabriela e com seu aluno, Paulo.

Após assistir ao primeiro trecho, a professora comentou que o aluno tem muito pouco interesse nas atividades pedagógicas propostas e que, por esse motivo, o trabalho estava voltado para o esquema corporal, com uso de músicas e brincadeiras para atrair mais sua atenção. Sinalizou que o aluno gosta de assistir a vídeos de futebol, mas que, exceto isso, não demonstra qualquer vontade de interação com a professora.

Em Face do exposto, a pesquisadora indagou a professora sobre a dificuldade do aluno em aceitar a sua proposta de atividade para aquele momento do atendimento. Além disso, perguntou de que forma ela poderia tentar mudar para que surgisse esse interesse no aluno e ela conseguisse realizar alguma atividade dirigida com o Paulo. Ademais, seria importante mostrar ao aluno que aquele 
momento era para realizar a atividade proposta, e não para ver o vídeo que ele queria. A professora respondeu que não saberia dizer como proceder e que, por esse motivo, teve tantas dificuldades no trabalho com ele, sentindo-se muito perdida em propor alguma coisa. Sinalizou que talvez com comida ele respondesse melhor a alguma atividade, pois ele gosta muito de comer.

Após a autoscopia, iniciou-se o momento teórico da formação continuada, no qual foi discutida a importância de utilizar um painel da rotina escolar na Sala de Recursos, principalmente no atendimento aos alunos com TEA, uma vez que a organização do tempo e das tarefas é fundamental para orientar essa clientela. A necessidade foi observada nas sessóes das filmagens iniciais, nas quais se verificou que nenhuma professora fazia uso desse material.

\section{Encontro 2}

No encontro 2 foi apresentada a segunda filmagem inicial às professoras para a realização da autoscopia. A partir disso, será descrito um dos momentos de autoscopia realizado com a professora Maria e o aluno Victor, para exemplificar o momento inicial desse encontro de formação continuada.

$\mathrm{Na}$ ocasião, a pesquisadora informou que a proposta da atividade filmada pela professora naquele dia era que o aluno realizasse uma pintura com o uso da tinta guache. Após assistir ao primeiro trecho selecionado, a professora Maria explicou que ela fez uso da tinta como um material diferente para experimentar com o aluno, buscando envolver o movimento das mãos (no caso, com os pincéis oferecidos). Depois, continuou o uso da tinta usando os dedos do aluno para ver a sua aceitação com a textura da tinta.

$\mathrm{O}$ questionamento da pesquisadora foi em relação à dúvida da professora Maria na entrevista inicial sobre a dificuldade de começar a introduzir a Comunicação Alternativa nas atividades. Lembrando-se dessa dificuldade, a pesquisadora explicou à pro- 
fessora que ela poderia propor o uso da CAA naquele momento de atividade e solicitou que ela indicasse uma proposta de ação. A professora parou para refletir e teve dificuldades em pensar em algumas possibilidades. A pesquisadora, então, começou a sugerir algumas ideias para que a atividade pudesse ter sido realizada com mais interação entre professora e aluno a partir das estratégias da Comunicação Alternativa, tais como: fazer cartóes com as cores para perguntar ao aluno qual cor de tinta ele gostaria de usar, se ele gostaria de usar o pincel ou o dedo para pintar, se ele gostou da atividade ou não, entre outras possibilidades.

Após o momento de autoscopia, foi dada a continuidade da proposta de produçáo do painel de rotina para uso na sala de recursos das professoras a partir da elaboração de cartóes e do painel de suporte para viabilizar o uso do recurso nos próximos atendimentos. Entáo, as professoras pensaram nas atividades que desenvolviam com os alunos e quais os cartóes de CAA seriam convenientes para confeccionar. O material foi feito com figuras do site ARASAAC, impresso e plastificado, sendo fixado ao painel com o uso do velcro autocolante.

\section{Encontro 3}

Para dar início ao encontro 3, a pesquisadora apresentou as filmagens referentes à terceira sessão inicial para as professoras e as usou para o procedimento de autoscopia. Nesse encontro, a pesquisadora utilizou novamente as cenas da professora Gabriela atuando em um momento difícil com comportamentos inadequados de Paulo. Na cena em questão, o aluno estava sendo atendido junto a outro aluno (não participante da pesquisa) na sala de recursos. A pesquisadora perguntou à professora o motivo dessa estratégia, e ela sinalizou que foi uma tentativa de mudar o comportamento do aluno e de mantê-lo mais tempo preso à tarefa proposta. A pesquisadora completou que realmente percebeu o aluno mais atento 
e que, às vezes, ele observa o comportamento dos seus pares no mesmo ambiente e pode aprender com o outro também.

No momento teórico desse encontro foi proposto o uso de Comunicaçáo Alternativa e Ampliada como uma possibilidade de estabelecer a comunicaçáo com o aluno. Para tanto, foi oferecida a formação para uso do sistema PECS-Adaptado, desenvolvido por Walter (2000). Trata-se de um programa baseado nos pressupostos metodológicos do PECS (Picture Exchange Communication Symbol), originalmente desenvolvido por Bondy e Frost (1994) e adaptado pela referida autora no contexto do Currículo Funcional Natural.

\section{Encontro 4}

O momento de autoscopia foi realizado, inicialmente, com uma confrontação feita com a professora Sandra, após a visualização de um dos trechos selecionados pela pesquisadora, na atuaçáo com o aluno Marcos. Na ocasiáo, a professora comentava a dificuldade de realizar atividades com o aluno devido a problemas na comunicação oral e que ela adaptava muitas atividades com o apoio visual de figuras (imagens) para compreender suas respostas. A discussão do vídeo se encaminhou para as adaptaçóes das provas bimestrais oferecidas pela rede de ensino, nas quais era de responsabilidade das professoras do AEE fazer as adequaçóes necessárias para cada aluno atendido por elas. A proposta teórica desse encontro foi apresentar os conceitos filosóficos do Currículo Funcional Natural para as professoras e fomentar uma discussão sobre a viabilidade de oferecer os atendimentos aos alunos na sala de recursos com algumas estratégias baseadas no CFN.

\section{Encontro 5}

O encontro 5 teve início com a seleção de alguns trechos pela pesquisadora que mostravam as professoras atuando com os alunos. 
Para esse encontro, foram usados vídeos da fase de pós-capacitação (que será descrita mais adiante), os quais as professoras filmavam já com o procedimento de autoscopia em andamento, ou seja, elas estavam filmando suas práticas após receberem algumas orientaçôes e ter havido trocas de informaçóes nos encontros iniciais da formação continuada.

Em um dos vídeos, a pesquisadora mostrou a atuação da professora Maria com o aluno Victor. O trecho da filmagem mostrava a professora propondo a organização das atividades realizadas com o aluno naquele dia de atendimento. Desse modo, ela colocou as propostas de todas as tarefas em ordem, organizando a rotina daquele dia. Foi questionado à Maria qual seria a intençáo da proposta, e a professora respondeu que, após um dos encontros da formação continuada, observou que o aluno poderia se organizar melhor no atendimento se ele tivesse uma rotina estabelecida para aquele dia de atendimento. Mesmo sem ter o material de CAA pronto para uso, ela pegou todas as tarefas daquele dia e organizou na ordem, apresentando ao aluno o que aconteceria naquele dia.

Após o momento de autoscopia, houve a continuidade do encontro anterior, com uma ênfase maior nos objetivos das atividades propostas pelas professoras aos alunos na sala de recursos. Discutiu-se sobre o planejamento das atividades a serem desenvolvidas e com qual propósito cada uma é criada. O objetivo foi mostrar às professoras a importância de associar os conceitos trabalhados naquela atividade planejada para uma funcionalidade da vida prática dos alunos.

\section{Encontro 6}

O encontro 6 não teve a realização do procedimento de autoscopia, por ter sido a realizaçáo de uma entrevista final a partir de um questionário semiestruturado, aplicada a todas as professoras participantes, que se deu de forma coletiva. $\mathrm{Na}$ ocasiáo, a pesqui- 
sadora perguntou sobre a experiência de cada uma de ter passado pelo procedimento de autoscopia; quais as possíveis mudanças na postura e nas atitudes delas; e que mudanças poderia causar nos alunos. Elas também deveriam responder o que foi mais marcante que aconteceu ao longo dos meses de capacitaçáo.

\section{c. Pós-capacitação}

Concomitantemente ao início do curso de capacitação, foi solicitado às professoras de AEE que continuassem a realizar as filmagens com os seus respectivos alunos. Esses vídeos foram classificados como sessôes de filmagens pós-capacitação. O objetivo da continuidade da filmagem foi verificar se as professoras mudariam a sua forma de atuar com os alunos após as dicas e sugestóes recebidas nas sessóes de autoscopia, bem como a partir das discussóes teóricas dos encontros que foram ocorrendo ao longo das sessôes de capacitação.

\section{d. Tratamento dos dados}

Foram analisadas as filmagens das sessóes de atendimento realizadas pelas professoras de AEE com os respectivos alunos, comparando as filmagens iniciais e as que ocorreram pós-capacitação. Os dados foram tratados numa abordagem qualitativa, sendo discutidos a partir da estruturação de categorias formuladas atendendo à proposta do $\mathrm{CFN}$, com foco nos procedimentos de ensino das professoras e nas características de TEA dos participantes alunos. As categorias foram observadas antes e depois do curso de formação continuada, verificando a eficácia do curso mediante as mudanças atitudinais e de comportamento dos participantes. 


\section{Resultados}

A partir das observaçôes das categorias, foi possível verificar mudanças nas posturas atitudinais das professoras e no comportamento dos alunos após o curso de formação continuada oferecido às professoras para a consolidação deste estudo. A seguir, serão descritos os resultados da mudança na atuação das participantes professoras de AEE após receberem a formação continuada, bem como seráo analisados os resultados no comportamento dos participantes alunos.

Tendo sido a proposta a realização de uma formação continuada das professoras de AEE para a sensibilização às estratégias de ensino baseadas no Currículo Funcional Natural, algumas instruçóes foram oferecidas ao longo dos encontros no intuito de favorecer e o ensino e a relaçáo com os alunos. Portanto, serão apresentadas as principais mudanças nas fases de filmagem inicial e na de pós-capacitaçáo das participantes professoras.

1. Uso de feedbacks: uma das propostas de procedimentos de ensino do CFN é a oferta de elogios quando o aluno tiver algum comportamento adequado, garantindo que ele compreenda qual é o comportamento desejável naquela situação (Suplino, 2009). ${ }^{12}$ Além disso, a autora (p. 68) sinaliza que "as habilidades dos alunos devem ser mais enfatizadas que suas fraquezas. $\mathrm{O}$ 'não' deve ser pouco enfatizado".

Portanto, com base nessa categoria, foi possível verificar as posturas das professoras em relação ao uso dos feedbacks (positivos, negativos ou corretivos). Nesse caso,

${ }^{12}$ Entende-se por feedback o comentário feito pela professora para dar retorno ao aluno acerca do comportamento ou da ação realizados por ele, ou seja, é uma resposta dada pela professora ao aluno para enfatizar uma ação que ele realizou durante uma tarefa ou por meio de um comportamento. O feedback pode ser positivo, negativo ou corretivo. 
observou-se que tanto a professora Gabriela como a professora Sandra tiveram um aumento na oferta do feedback positivo, desde a fase de filmagem inicial até a filmagem pós-capacitação.

2. Aguardar a resposta do aluno: esse é um recurso importante na relação com o aluno, visto que o professor deve manter a calma. Suplino (2009) descreve que na proposta do CFN também é sugerido ao professor que mantenha essa conduta. Segundo a autora (p. 69), "deve ser dado tempo suficiente para a resposta do aluno”. Em relação a essa categoria, notou-se a mudança na postura da professora Gabriela, que passou a aguardar mais pelas respostas de Paulo, o que se pode verificar nas filmagens após ter recebido dicas da pesquisadora nos encontros de capacitação.

3. Uso de cartôes de CAA: este passou a ser realizado em dois momentos mais significativos das atividades, a saber: na rotina de atividades na sala de recursos e no treinamento do uso do PECS-Adaptado. Verificou-se que tanto a professora Maria quanto a professora Gabriela iniciaram o uso de recursos da CAA somente após receberem a capacitação, visto que as suas filmagens iniciais náo mostram qualquer ocorrência de uso da Comunicação Alternativa. A professora Sandra, por sua vez, fez o uso do cartão BANHEIRO em uma sessão de filmagem inicial para perguntar ao aluno Marcos se ele gostaria de ir ao banheiro. O aumento de ocorrência na fase de filmagem pós-capacitação se deu devido ao uso dos cartôes de rotina e do programa de comunicação alternativa baseado no PECS-Adaptado. 
4. Ignorar comportamentos inadequados e redirecionar para outra atividade: segundo Suplino (2013, p. 29), redirecionar é uma forma de intervenção que consiste no "(re)direcionamento da atenção da pessoa que está manifestando o comportamento inapropriado a um outro comportamento ou tarefa mais adequados". Foi possível observar, ao longo das sessóes, se as professoras redirecionavam ou não os alunos para outras atividades, ignorando os comportamentos inadequados nas duas fases de investigação. Com isso, notou-se que a professora Gabriela sofria com constantes atitudes inadequadas de Paulo (como puxar o cabelo dela, bater, arremessar objetos no chão da sala de recursos, jogar-se ao chão). Com o curso de formação, a professora foi orientada a redirecionar mais os comportamentos e/ ou ignorar para que o aluno entendesse as atitudes que eram adequadas.

Além dos resultados descritos acima, também foram verificadas mudanças significativas nas professoras em diferentes aspectos. Perceberam-se modificaçóes em relação ao uso da rotina. Por conseguinte, as professoras começaram a se organizar nas tarefas propostas para aquelas sessóes com os alunos. Em depoimento nos encontros, a professora Maria relatou que o aluno Victor, no início, não havia entendido a proposta do uso de cartóes da rotina, mas, nos dias seguintes, o aluno já buscava pelos cartóes da rotina para se organizar nas atividades, compreendendo a sequência de práticas propostas pela professora.

Notou-se também um aumento na produção de atividades pedagógicas, principalmente nas mudanças das propostas da professora Gabriela com o aluno Paulo. A professora contou, na entrevista inicial, que "não tinha muito o que fazer" com o aluno, pois ele não atendia às suas solicitaçóes e que precisava se organizar primeiro, pois nunca havia frequentado escola anteriormente, e 
tudo era "novo e diferente". Ela se dizia "sem ideias" para trabalhar com o aluno na sala de recursos. Com as sessôes de autoscopia, as professoras viam a rotina e as atividades propostas pelas colegas e conseguiam ter mais ideias para produção de material nas respectivas salas de recursos, tanto para os alunos sujeitos da pesquisa como para outros alunos que atendiam no AEE.

Houve também uma preocupação por parte das professoras Gabriela e Sandra em pensar atividades voltadas para a faixa etária dos seus respectivos alunos. Nos encontros das formaçóes, a pesquisadora mencionou o fato de as professoras infantilizarem as suas propostas pedagógicas com músicas e/ou atividades que não condiziam com as idades cronológicas desses estudantes.

As professoras também experienciaram uma entrevista final para avaliar e criticar a investigação e o desencadeamento da pesquisa para a vida profissional delas. Todas afirmaram estar satisfeitas com o formato da pesquisa e com a oportunidade de terem se filmado para que sua prática fosse analisada por elas e por outras pessoas. As professoras consideraram o procedimento de autoscopia válido e eficaz para apontar em que elas podem melhorar e para mudar alguns conceitos em relação aos seus alunos.

Um ponto de destaque na entrevista final foi saber que as professoras começaram a generalizar o uso dos procedimentos de ensino aprendidos para os demais alunos. Ademais, compartilharam esse conhecimento com outras professoras. Elas também ampliaram as açóes para além da Sala de Recursos Multifuncional: a professora Maria elaborou uma rotina para o aluno Victor usar na turma regular, assim como a professora Sandra produziu mais cartóes de CAA para Marcos usar com a sua mediadora escolar na sala de aula. A professora Gabriela começou a elaborar atividades mais funcionais e de acordo com a faixa etária, não somente para Paulo, mas para seus outros alunos também atendidos na sala de recursos. 


\section{Discussáo}

A formação continuada para professores é fundamental para que o processo de inclusão escolar seja mais eficaz, buscando ressignificar as práticas pedagógicas e trazer melhores estratégias de intervenção com os alunos, sejam eles da educação especial, sejam mesmo do ensino comum. Em relação à autoscopia, esse uso foi bem avaliado pelas professoras participantes e apontado como um eficaz procedimento de repensar a prática pedagógica. Esse fato vai ao encontro dos achados de Silva (2016, p. 8), visto que, para a autora, "a autoscopia provocou a mudança na prática pedagógica das professoras, pois elas tiveram a oportunidade de serem formadas de acordo com os conflitos que emergiam de suas práticas”.

O cartão de Comunicação Alternativa e Ampliada foi outro recurso de que as professoras começaram a se apropriar e a fazer uso ao longo dos atendimentos com os alunos. Mesmo com o pouco conhecimento prático e ainda com a insegurança de "errar" no uso com os alunos, as professoras decidiram construir os cartóes. Para tanto, selecionaram o vocabulário que achavam mais adequado e necessário ao contexto da sala de recursos e, após o encontro de capacitação sobre a utilização do uso do PECS-Adaptado, iniciaram o uso. Tais dados corroboram com os achados de Walter e Nunes (2013), onde os professores das salas do AEE relatam a importância de organizarem e se responsabilizarem pela confecção de cartões de CAA e colocarem em prática o uso da CAA.

Também foi percebida a mudança nas atitudes da professora Gabriela, que passou a propor atividades mais funcionais e de acordo com a faixa etária do aluno Paulo. Partindo dos interesses do aluno, conforme propóe as práticas do CFN, professora e pesquisadora propuseram-se a pensar atividades que estivessem de acordo com a faixa etária e no âmbito de maior interesse do aluno, que, no caso, era o futebol. De acordo com Suplino (2009, p. 71), “os interesses do aluno devem ser aproveitados para o ensino de novas 
habilidades". O CFN tem a proposta de ensinar os conhecimentos e as habilidades que possam ser úteis para a vida do educando, priorizando o ensino e a generalização dos comportamentos aprendidos em ambientes reais e naturais (Walter, 2017) e propondo outra abordagem de ensino no espaço escolar.

Nesse sentido, as novas posturas e práticas adotadas pelas professoras, baseadas nos modelos de ensino do CFN, puderam ser observadas ao final desta investigação. Como resultado, aponta que a inclusão de pessoas com TEA é uma realidade no âmbito educacional. No entanto, mesmo com a garantia de acesso e permanência nos espaços escolares pela legislação brasileira, ainda há muita dificuldade em receber os alunos e lhes oferecer uma educação de qualidade.

Com este estudo, foi possível verificar a importância da oferta de cursos de formação continuada para capacitar as professoras com novas práticas pedagógicas que têm se mostrado eficazes para atender à demanda do atual paradigma da inclusão escolar. Ademais, no atendimento aos professores em formação, as capacitaçóes com propostas mais individualizadas parecem ter melhor resultado.

Nesse processo, o uso de recursos de Comunicação Alternativa e Ampliada aliados ao procedimento do PECS-Adaptado se mostrou como possibilidade de incentivo a uma forma de comunicação alternativa para alunos que não apresentam fala funcional no contexto escolar. Por fim, foi possível verificar a aplicação de práticas e concepçóes do Currículo Funcional Natural no contexto escolar, mesmo que ainda de modo inicial e tímido, mas que já começaram a gerar mudanças nas práticas pedagógicas das professoras do Atendimento Educacional Especializado.

\section{Consideraçóes finais}

Foi possível observar a importância do uso da autoscopia no processo de formação continuada de professores do AEE, pelo 
processo de análise e reflexão das práticas pedagógicas e na possibilidade de mudanças pautadas na real necessidade dos alunos com TEA incluídos na escola regular. Promover melhores condiçôes de comunicação e interação social entre alunos com TEA e seus pares e professores deve ser uma preocupação constante para obtenção do êxito no processo de inclusão escolar.

Como já citado anteriormente, o presente capítulo descreveu um recorte de uma tese de doutorado e, provavelmente, muitos outros estudos devem ser encorajados nessa temática, com o intuito da promoção de novas técnicas e procedimentos baseados em evidências científicas.

\section{Referências}

BONDY, A. et al. The picture exchange communication system. Cherry Hill, NJ: Pyramid Educational Consultants Inc, 1994.

BRIDI, F. R. S. "Formação continuada em educação especial: o atendimento educacional especializado". Revista do Programa de Pós-Graduação em Educaçâo - mestrado - Universidade do Sul de Santa Catarina, v. 4, n. 7, jan.-jun. 2011.

CUCCOVIA, M. M. Análise de procedimentos para avaliação de interesses baseado em um currículo funcional natural e seus efeitos no funcionamento geral de individuos com deficiência mental e autismo (dissertação). Universidade Federal de São Carlos, 2003.

GIARDINETTO, A. R. S. B. Comparando a interação social de crianças autistas: as contribuiçóes dos programas TEACCH e do Currículo Funcional Natural (dissertação). Universidade Federal de São Carlos, 2005.

LEBLANC, J. M. Enseñanza Funcional/Natural para la generalización y mantenimiento de las habilidades para niños con autismo y retardo mental. Universidade de Kansas e Centro de Educação Especial Ann Sullivan, Peru, 1982.

MAYO, L. et al. "Centro Ann Sullivan del Perú (CASP): un programa educativo desarrollado para enseñar a personas con habilidades a ser independientes, productivos y felices - mostrar lo que pueden hacer, y ser incluidos en todas las actividades de la vida como un miembro valioso de la sociedad. Revista Teias, ano 9, n. 18, Rio de Janeiro, jul.-dez. 2008. 
NUNES, L. R. O. P. "Comunicação alternativa: uma introdução". In (org.). Favorecendo o desenvolvimento da comunicação em crianças e jovens com necessidades educacionais especiais. Rio de Janeiro: Dunya, 2003, pp. 3-13.

SADALLA, A. M. F. A e LAROCCA, P. "Autoscopia: um procedimento de pesquisa e de formação". Educação e Pesquisa, v. 30, n. 3, pp. 419-33, São Paulo, set.-dez. 2004.

SILVA, A. F. et al. "Formação de professores e educação da pessoa com deficiência: mapeamento das produçôes acadêmicas nas pós-graduaçóes do Brasil". Anais do 90 Encontro Internacional de Formação de Professores, v. 9, n. 1, 2016. SILVA, T. M. A Autoscopia como ferramenta para a formação continuada de professores de Sala de Recursos Multifuncionais (dissertação). Universidade do Estado do Rio de Janeiro, 2016.

SUPLINO, M. "A inclusão de pessoas com autismo em escola regular: desafios e possibilidades". In NUNES, R. P. O. P. et al. (orgs.). Ensaios sobre autismo e deficiência múltipla. Marília: ABPEE: Marquezine \& Manzini, 2013, pp. 161-70.

. Currículo funcional natural: guia prático para a educação na área do autismo e deficiência mental. Rio de Janeiro: Secretaria Especial dos Direitos Humanos, Coordenadoria Nacional para a Integração da Pessoa Portadora de Deficiência; Rio de Janeiro: CASB-RJ, 2009.

WALTER, C. C. Os efeitos da adaptação do PECS associada ao curriculum funcional em pessoas com autismo infantil (dissertação). Universidade Federal de São Carlos, 2000.

. "Reflexóes sobre o currículo funcional/natural e o PECS-Adaptado no processo de inclusão do aluno com autismo". Inc. Soc., v. 10, n. 2, pp.132-40, Brasília, DF, jan.-jun. 2017. 